\title{
A ONTOLOGIA DO FONEMA NA LINGUÍSTICA CONSTRUTURAL DE BACK (1923-2003) E MATTOS (1931-2014)
}

\author{
Alessandro Jocelito BECCARI ${ }^{1}$
}

\begin{abstract}
Resumo: A cidade de Curitiba foi um dos primeiros locais no Brasil onde a Linguística tornou-se disciplina universitária. Já nos anos 1950, a Universidade do Paraná formava seus estudantes em contato com teorias linguísticas. Em 1953, foram criados o Círculo Linguístico de Curitiba e a Revista Letras. Nos anos 1960, na então Universidade Católica do Paraná, os professores Eurico Back (1923-2003) e Geraldo Mattos (19312014) propuseram uma teoria de cunho estruturalista denominada Linguística Construtural (LC), desenvolvendo literatura substancial e formando uma geração de linguistas (BORGES NETO, 2013, p. 17). O objetivo deste artigo é refletir sobre um conceito central da LC: a noção de fonema. Para isso, serão examinados alguns trabalhos de Back e Mattos, em especial, a Gramática construtural da língua portuguesa de 1972 e seu Manifesto, publicado no primeiro número da revista Construtura, e também uma entrevista feita com Mattos em 2011. Na análise, assumese a atribuição de importância fundamental a entidades teóricas para a compreensão epistemológica dos pressupostos básicos das teorias linguísticas, tese defendida por Borges Neto (1991; BORGES NETO; DASCAL, 2004) e Dascal (1978).
\end{abstract}

Palavras-chave: Historiografia Linguística. Filosofia da Linguística. Linguística Construtural.

\section{Introdução}

A pesquisa científica sempre assume entidades teóricas que colocam um problema recorrente para a epistemologia:

\footnotetext{
${ }^{1}$ UNESP - Universidade Estadual Paulista “Júlio de Mesquita Filho” - Departamento de Linguística. Assis - São Paulo - Brasil. 19806-900 - jbeccari@assis.unesp.br 
[...] a natureza dessas entidades. São elas tão "reais” quanto observáveis? Ou são apenas conceitos úteis para a descrição/explicação dos observáveis sem apresentarem, no entanto, nenhuma "realidade"?

As repostas a estas perguntas constituem o que tradicionalmente se chama de problema ontológico. (BORGES NETO; DASCAL, 2004, p. 37-38)

O problema ontológico surge no contexto do debate filosófico da Idade Média, em que um universal é entendido como um conceito que possui aplicabilidade geral ou universal: o conceito de gênero (por exemplo, “animal”), o conceito de espécie (por exemplo, "homem”, “cavalo”), o conceito de diferença específica (por exemplo, “racional”)2. Além disso, os nomes de propriedades (como "brancura”, "humano”, “equino”, etc.) e os nomes das coisas do mundo a que as espécies se aplicam (como “mesa”, “árvore”, “estátua”, etc.), também são considerados universais (GILSON, 1998 [1922]). O debate medieval sobre que tipo de existência atribuir aos universais ganhou o nome de "querela dos universais" e deu origem a três posicionamentos: o realista, que atribui existência real aos universais; o conceitualista, que lhes atribui uma existência pelo menos mental; o nominalista, que não lhes atribui qualquer tipo de existência (BORGES NETO; DASCAL, 2004, p. 38).

Para nominalistas como Guilherme de Ockham (c. 1287-1347), que estudou a referência dos termos da proposição, na lógica, a resposta para o problema ontológico está na referência entre termos e coisas: se para cada termo da linguagem existir uma e somente uma coisa no mundo, o problema estará resolvido: “é o mesmíssimo o objeto do sentido e do intelecto" (OCKHAM, 1979 [c. 1327], p. 358). Assim, para Ockham, o universal é simplesmente o nome de uma coisa. Para realistas moderados como João Duns Scotus (c. 1266-1308), existe uma classe de universais reais que independem do intelecto humano: "Platão [...] menciona no Timeu um exemplar fabricado e um não fabricado [...] o exemplar criado é a representação universal causada pela coisa; o exemplar incriado é a idéia na mente divina.” (SCOT, 1979 [c. 1300], p. 247). Para realistas como Duns Scotus, os universais da mente divina são anteriores ao mundo ${ }^{3}$. Tomás de Erfurt (1972, fl. 1310), um conceitualista, procura resolver o problema

\footnotetext{
${ }^{2}$ Na filosofia medieval, os gêneros diferenciam-se em espécies por meio de diferenças específicas. Assim, por exemplo, "cavalo" e "homem” são espécies do gênero "animal” que se diferenciam por meio de uma diferença específica da espécie "homem”: "racional”.

${ }^{3}$ Grosso modo, os realismos medievais podem ser definidos como platonismos: os universais são entendidos como anteriores ao mundo: ideias na mente divina.
} 
ontológico com uma classe de objetos mentais: os modos como o intelecto humano percebe a realidade. Para Tomás de Erfurt, os conceitos são os modos da mente humana entender as propriedades das coisas do mundo: esses modos são tão reais quanto as propriedades das coisas entendidas (ERFURT, 1972 [c.1310]). Para conceitualistas como Tomás de Erfurt, os universais têm existência real na mente humana ${ }^{4}$.

Apesar de parecer distanciado no tempo, o debate que a Idade Média inaugurou sobre a realidade de um tipo de universal persiste na Linguística contemporânea na forma de atribuições de existência ou inexistência a entidades teóricas. A universalidade dos gêneros e espécies da filosofia medieval continua a ter algum tipo de existência nos termos teóricos da Linguística atual como, por exemplo, nas espécies naturais da Semântica Formal, de acordo com Chierchia (1998, p. 345-352), nos universais do comportamento humano da Tagmêmica de Kenneth Lee Pike (1982 [1977], p. 1-6), nas premissas do sistema dedutivo de Louis Hjelmslev (1975 [1943], p. 15-17). Entretanto, como será visto nos parágrafos a seguir, diferentemente da Idade Média, as soluções para o problema ontológico ganharam uma “certa complicação” na Linguística contemporânea (BORGES NETO; DASCAL, 2004, p. 39).

Segundo Borges Neto e Dascal (2004), um exemplo de recorrência do problema ontológico na história dos estudos da linguagem foram as diferentes maneiras de entender o fonema por parte de linguistas como Leonard Bloomfield (1887-1949) e Edward Sapir (1884-1939) e de entender a gramática como sistema em Saussure (18571913), Hjelmslev (1899-1965) e Chomsky (n. 1928) ${ }^{5}$. Dos autores citados por Borges Neto e Dascal (2004), Sapir, Bloomfield e Pike representariam, respectivamente, ontologias conceitualistas, nominalistas e realistas dos estudos da linguagem no Estruturalismo Norte-americano do séc. XX.

\footnotetext{
${ }^{4}$ Em sua teoria da linguagem, Tomás de Erfurt estabeleceu uma série de correspondências entre entidades mentais, que chama de modos de entender e modos de significar e propriedades do mundo, que chama de modos de ser: os modos de ser das coisas correspondem aos modos de entender do intelecto e estes correspondem aos modos de significar da linguagem. Ao correlacionar mundo, mente e linguagem, a teoria de Tomás de Erfurt pode ser classificada como um "programa de correspondência" na história dos estudos da linguagem (SWIGGERS, 2003, p. 130).

${ }^{5}$ Em seu ensaio Models in Linguistic Historiography, Koerner assume recorrências de problemas na história dos estudos da linguagem e discute um modelo historiográfico adequado para a abordagem dessas recorrências (1989, p. 53). O problema ontológico parece representar não apenas uma das questões linguísticas mais comuns na história dos Estudos da Linguagem, mas também um dos principais temas a serem tratados pela Filosofia da Linguística.
} 
Embora útil, a classificação medieval das soluções ao problema ontológico requer uma certa elaboração para poder ser aplicada hoje em dia. Em primeiro lugar, é preciso observar que nenhuma teorização pode abrir mão de generalizações. Estas, por sua vez, sempre implicam na identificação de relações entre os dados, ou seja, o conjunto de dados torna-se necessariamente 'estruturado' por um conjunto de relações. Até mesmo um nominalista declarado, como Bloomfield, em seu 'A set of postulates for the science of language' (1926), descreve na verdade um conjunto de estruturas relacionais. A questão é saber, então, que tipo de 'realidade' atribuir a essas estruturas. (BORGES NETO; DASCAL, 2004, p. 41)

A “querela dos universais linguísticos” pode ser relacionada à “querela sobre a realidade das estruturas linguísticas”, em particular sobre uma dessas estruturas: o fonema.

Nas seções a seguir, serão discutidas as ontologias do fonema em textos clássicos de Leonard Bloomfield, Edward Sapir e Kenneth Lee Pike. Na seção seguinte, será discutida a ontologia do fonema na Linguística Construtural (LC) de Back e Mattos. Nas “Considerações Finais”, a partir das teorias apresentadas nas seções anteriores, será verificada de qual das três soluções para o problema ontológico do estruturalismo norte-americano a LC mais se aproxima e, consequentemente, se a LC se assemelha mais ao nominalismo de Bloomfield, ao realismo de Pike ou ao conceitualismo de Sapir no que se refere à ontologia do fonema.

\section{O fonema no Estruturalismo Norte-americano}

A primeira pergunta que se poderia colocar a este artigo seria: por que estudar a ontologia de um termo teórico como o fonema em uma teoria linguística brasileira que parece ter sido muito influenciada pelo estruturalismo norte-americano ${ }^{6}$ ? A resposta a essa pergunta pode vir dos estudos da linguagem do século XIX:

\footnotetext{
${ }^{6}$ Eurico Back (1923-2003), um dos dois criadores da Linguística Construtural, foi discente de uma das primeiras turmas do primeiro curso de especialização em Linguística do Brasil, implantado pelo, também paranaense, Ayron Rodrigues (1925-2014) na Universidade de Brasília (UnB) em 1963. O mestrado em Linguística foi iniciativa do então ministro da educação, Darcy Ribeiro (1922-1997) e foi possível através de um convênio que este firmou com o Summer Institute of Linguistics (SIL), uma organização confessional norte-americana. O então presidente do SIL, Kenneth Lee Pike (1912-2000), foi o criador da Tagmêmica, uma das principais teorias da tradição estruturalista norte-americana. Eurico Back notabilizou-se entre seus colegas por ter sido "o único capaz de ler Bloomfield de ponta a ponta (DP (depoimento) agosto de 1992)” (ALTMAN, 1998, p. 117). Segundo Geraldo Mattos - em entrevista concedida em abril de 2011 -, durante anos, Eurico Back aplicou o método descritivo da Tagmêmica a
} 
Partindo de idéias isoladas e pouco desenvolvidas, mas às vezes bem inspiradas, que prevaleceram nos primeiros anos, os lingüistas do período oitocentista construíram uma teoria e um modelo capazes de representar a história das línguas e elaboraram um método capaz de servir como fio condutor das pesquisas. Embora estivessem precipuamente voltados para a família indo-européia, que alcançou nessa época contornos bem definidos, esses lingüistas configuraram um esquema que, apesar de alguns indispensáveis reparos, tem sido proveitosamente aplicado a outros grupos lingüísticos, como ao [...] grupo algonquino, de cujo passado não havia nenhum registro escrito. Sob todos os pontos de vista, foram de grande valor as conquistas do século XIX, e se pode atribuir boa parte dessas conquistas aos estudos lingüísticos desenvolvidos pelas universidades alemãs, merecedoras, com toda justiça, da fama de que então desfrutavam. (ROBINS, 1983 [1967], p. 155-156)

Segundo Robins (id., p. 161), uma das linhas principais do contexto cultural da Linguística alemã do séc. XIX, que teve uma influência definidora nos rumos dos estudos da Linguística norte-americana do séc. XX, foram os estudos de Fonética e Fonologia. Robins atribui a emergência desses estudos na Linguística alemã do séc. XIX a uma "valorização progressiva do saber linguístico hindu, especialmente na parte da fonética e da fonologia” (ibidem). De acordo com Rogers (1989, p. 89), a influência hindu apontada por Robins é confirmada, pois parece, de fato, fazer parte da origem do estabelecimento do paradigma estruturalista norte-americano:

Leonard Bloomfield's Language (1933) is considered the initial work in the establishment of the American structuralist paradigm. It is known that Bloomfield studied the grammar of Sanskrit composed by Pānini, who lived approximately in the sixth century B.C. in India. His 'On Some Rules of Pānini” (1927) is a detailed technical analysis of certain statements of Pānini's grammar concerning pronouns.

O estudo das línguas nativas norte-americanas na primeira metade do séc. XX como, por exemplo, as descrições de línguas algonquianas por Bloomfield (1933) e das uto-aztecas por Sapir (DARNELL, 1990, p. 130) - proporcionou um novo objeto para os estudos linguísticos descritivos de viés fonético e fonológico. O Estruturalismo Norte-americano, portanto, não rompeu com a tradição descritivista iniciada na Europa no século anterior. Nem essa mudança de objeto implicou em um abandono completo da parentesco entre a Linguística Construtural e o estruturalismo norte-americano. 
perspectiva diacrônica da Linguística alemã. O vigésimo capítulo de Language (1933) é um estudo sobre mudança fonética: seu título original é Phonetic Change e nele Bloomfield discute exemplos do anglo-saxão, do latim, do sânscrito, do gótico ao lado de comparações com as línguas algonquianas: ojibwa, menomini e cree (BLOOMFIELD, 1961 [1933], p. 381). Esse desenvolvimento norte-americano de procedimentos de análise fonética e fonológica, que vinham sendo desenvolvidos há mais de um século pela Linguística alemã, parece fazer parte do que Robins chama de "efeitos mais imediatos e historicamente importantes" que o pensamento de Saussure produziu (ROBINS, 1983 [1967], p. 164).

Devido à importância dos estudos fonéticos e fonológicos no Estruturalismo Norte-americano, que foram amplamente acolhidos pela Linguística brasileira dos anos 1960 (ALTMAN, 2004 [1998], p. 116-124), considerações acerca das definições de fonema na Linguística norte-americana parecem pertinentes para o estabelecimento dos pressupostos do termo teórico “fonema” na LC.

\section{O fonema em Bloomfield}

Leonard Bloomfield (1887-1949), em seu clássico Language (1933), apresenta o fonema como uma espécie de abreviação para conjuntos de comportamentos fisiológicos idênticos. De acordo com Bloomfield (1961 [1933]), esses comportamentos, eventualmente, poderiam ser explicados pela Fisiologia e pela Psicologia. Segundo o mesmo autor, os fonemas são traços acústicos distintivos substancializados em feixes de sons:

These distinctive features occur in lumps or bundles, each one of which we call a phoneme. The speaker has been trained to make sound-producing moviments in such a way that the phoneme-features will be present in the sound-waves, and he has been trained to respond only to these features and to ignore the rest of the gross accoustic mass that reaches his ears. (BLOOMFIELD, 1961 [1933], p. 79)

Os fonemas de Bloomfield são, portanto, etiquetas que marcam cada um dos traços distintivos mínimos, audíveis no contínuo da fala de uma determinada língua. $\mathrm{O}$ falante e o ouvinte da mesma língua estariam treinados tanto a perceber quanto a produzir esses traços distintivos devido à repetição de processos físicos de estímulos 
auditivos e reações do aparelho articulador, o que possibilitaria ao falante e ao ouvinte identificarem esses traços distintivos e, assim, diferenciá-los entre si.

Como resultado do empirismo na fonologia, pode-se dizer que, para Bloomfield, só os sons têm existência real (empírica) - os fonemas seriam as etiquetas convencionais desses sons e, portanto, um fonema não pode ser considerado como uma entidade com existência própria.

Na medida em que não atribui qualquer tipo de existência ao fonema, Bloomfield é um nominalista nos Estudos da Linguagem. E é também um empirista, pois o “objeto teórico da [sua] lingüística é povoado apenas por fenômenos observáveis: os sons da fala” (BORGES NETO, 2004, p. 40). Talvez por isso, a definição de “significados” (meanings), de acordo com Bloomfield, é o ponto fraco dos estudos da linguagem: "The statement of meanings is therefore the weak point in language-study, and will remain so until human knowledge advances very far beyond its present state” (BLOOMFIELD, 1961 [1933], p. 140). É um ponto fraco porque, da perspectiva do nominalismo empirista de Bloomfield, para que a Linguística estabelecesse cientificamente (positivamente) a referência de cada uma das formas (speech-forms) de uma determinada língua, seria necessário um conhecimento científico preciso para cada uma das coisas (e situações) a que essas formas correspondessem no mundo do falante:

The situations which prompt people to utter speech, include every object and happening in their universe. In order to give a scientifically accurate definition of meaning for every form of a language, we should have to have a scientifically accurate knowledge of everything in the speakers' world. The actual extent of human knowledge is very small, compared to this. (BLOOMFIELD, 1961 [1933], p. 139)

Embora Bloomfield reconheça a impossibilidade de um mapeamento exaustivo imediato de cada um dos significados de cada uma das formas da fala de uma língua, ele acredita que, em um futuro imaginável de ciência quase perfeita, as ciências avançarão a ponto de dar conta das denotações empíricas de todos esses significados:

The meanings of speech-forms could be scientifically defined only if all branches of science, including, specially psychology and physiology, were close to perfection. Until that time, phonology and, with it, all the semantic phase of language study, rests upon an assumption, the fundamental assumption of linguistics: we must 
assume that in every speech-community some utterances are alike in form and meaning. (id., p. 78)

Portanto, como Bloomfield reconhece a impossibilidade de levar seu nominalismo empirista às últimas consequências, ele dá auto-consistência a seu sistema com uma solução prática: uma "assunção fundamental da lingüística”, que significa assumir a seguinte premissa: para cada forma linguística existirá um e somente um

significado e, consequentemente, não existirão sinônimos reais: “Our fundamental assumption implies that each linguistic form has a constant and specific meaning. [...] We suppose in short that there are no actual synonyms" (ibid., p. 145).

\section{O fonema em Sapir}

Edward Sapir, em artigo de 1933, contrariamente a Bloomfield, afirma que o fonema não é apenas uma abreviação de sons distintivos: é uma atitude psicológica do falante. Tal atitude, segundo Sapir, não é apenas mais básica do que o som da fala, é também produto da "intuição" do falante:

If phonemic attitude is more basic, psychologically speaking, than the more strictly phonetic one, it should be possible to detect it in the unguarded speech judgments of native speakers who have a complete control of their language in the practical sense but have no rationalized or consciously systematic knowledge of it. (SAPIR, 1949 [1933], p. 47)

Sapir chegou à conclusão acima a partir de seu trabalho com um falante nativo do paiute do Sul (uma língua uto-azteca): Tony Tillohash (1888-1970). Segundo Darnell (1990, p. 134), Tillohash era o tipo de informante ideal para Sapir, pois seu inglês era adequado não só para o trabalho básico de tradução da língua em estudo, mas também porque ele tinha informações sobre a cultura de seu povo. Foi baseado nas intuições de Tony Tillohash que Sapir formulou sua noção de fonema: uma unidade psicológica a que o falante tem acesso de maneira intuitiva e que faz parte de seu patrimônio cultural. Para Sapir, essa unidade psicológica é um hábito ou padrão (pattern) a que o falante nativo tem acesso intuitivamente como membro de sua comunidade linguística: o 
falante participa intuitivamente dos hábitos sociais de sua comunidade e, dentre esses hábitos, dos hábitos fonêmicos de sua língua nativa.

Para Sapir, uma língua é uma realidade social e o mundo “objetivo” é construído em grande parte com base nos hábitos ou padrões linguísticos do grupo que utiliza essa língua:

\begin{abstract}
Language is a guide to 'social reality'[...] Human beings do not live in the objective world alone, nor alone in the world of social activity..., but are much at the mercy of the particular language which has become the medium of expression of their society [...] The fact of the matter is the 'real world' is to a large extent unconsciously built up on the language habits of the group. No two languages are ever sufficiently similar to be considered as representing the same social reality [...] We see and hear otherwise experience very largely as we do because the language habits of our community predispose certain choices of interpretation. (SAPIR, 1929, p. 207)
\end{abstract}

Portanto, para Sapir, o fonema é um hábito ou padrão (pattern) psicológico que o falante intuiria de sua realidade social e que não precisaria sempre fazer referência a qualquer dado empírico, como parece na fundamentação de Bloomfield. Assim, ao menos com relação à Fonêmica, Sapir pode ser classificado como um conceitualista em Linguística, pois para ele a projeção de categorias ou padrões linguísticos é identificada a partir da mente e interfere, de fato, na maneira como a mente filtra o mundo objetivo. Nesse sentido, objetos mentais (patterns) podem predefinir a percepção que o falante tem de sons: sua audição de traços constantes no contínuo dos enunciados de uma determinada língua, por exemplo. Talvez uma evidência a favor da fonêmica conceitualista de Sapir possa ser a dificuldade que muitos falantes adultos têm de entender ou produzir determinados sons no aprendizado de línguas estrangeiras.

Portanto, a interpretação do fonema em Sapir mostra-se diferente da apresentada em Bloomfield: enquanto o segundo parte de dados acústicos para construir sua teoria, o primeiro parte de padrões sociais que estariam, antes de tudo, na mente dos falantes de uma língua. 


\section{O fonema na Tagmêmica de Pike}

Kenneth Lee Pike (1912-2000), em seu Grammatical analysis (1982 [1976]) e em entrevista concedida a K. J. Franklin (1996), assume que todos os seres humanos possuem um conjunto inato de categorias mentais que são equivalentes a universais linguísticos e morais ${ }^{7}$. Como consequência disso, Pike considera que as análises que um linguista fará de uma língua (mesmo que ágrafa e desconhecida ou extinta) serão generalizações que, embora inicialmente apenas prováveis, poderão e deverão basear-se em princípios universais do comportamento humano, os quais podem e devem ser usados para a descrição satisfatória de todas as línguas naturais.

A unidade básica da Tagmêmica é o tagmema (uma palavra de origem grega (tágma, tagmátos) que significa “regra” e “disposição regular de elementos”8). Como a etimologia do termo indica, o tagmema tem dupla natureza: i) traços distintivos (features) que o distinguem como unidade (elemento); ii) uma determinada posição em uma construção "horizontal” com outros tagmemas (disposição regrada). Na Tagmêmica de Pike, essa construção de tagmemas é chamada de sintagmema (JONES, 1995, p. 317).

Em virtude de sua dupla natureza, o tagmema representa uma distinção “unidade-em-contexto" que pode ser aplicada a todas as unidades da língua: tanto fonemas e sílabas quanto morfemas, palavras, sentenças, parágrafos, monólogos e conversações. Um fonema, por exemplo, é uma unidade no contexto de uma palavra. O tagmema é, portanto, o building block ou princípio básico de construção do sistema criado por Pike.

As duas dimensões do tagmema lembram os termos da distinção saussureana entre relações sintagmáticas e relações associativas ou paradigmáticas (SAUSSURE, 2011 [1917], p. 142-147). Todavia, o tagmema representa uma generalização das intersecções dessas relações saussureanas, pois extrapola os fatos linguísticos e inclui os fenômenos culturais, já que fatos linguísticos são entendidos como comportamentos

\footnotetext{
${ }^{7}$ Kenneth Lee Pike combinou uma produção científica de destaque com uma reflexão antropológica de natureza confessional. Como se sabe, entre 1942 e 1979, Pike foi presidente do Summer Institute of Linguistics (SIL): uma organização cristã que tem como uma de suas metas a tradução da Bíblia para todos os idiomas do mundo. A partir de 1979, Pike foi presidente emérito do SIL até 2000, ano de sua morte.

${ }^{8} \mathrm{O}$ léxico de Liddell e Scott dá as seguintes acepções para essa palavra em grego antigo: "an ordinance, command. 2. A regular body of soldiers, a corps, division.” (1974 [1843], p. 689).
} 
culturais. Na Tagmêmica de Pike, os conceitos de unidade e de contexto são, de fato, universais do comportamento humano anteriores a todos os comportamentos culturais.

Durante boa parte do séc. XX, munido de uma teoria descritiva baseada no conjunto de princípios que derivou da distinção subjacente à noção de tagmema (unidade-em-contexto), Pike e seus associados foram a campo e descreveram, com sucesso, centenas de línguas vivas, ágrafas e minoritárias. Além disso, Pike também tentou estabelecer uma fundamentação antropológica que pudesse dar conta dos contextos sociais dos falantes das línguas descritas pela Tagmêmica ${ }^{9}$. A maneira como Pike entende a continuidade entre aspectos culturais e linguísticos parece clara a partir da leitura deste parágrafo do "Prefácio” à primeira edição de seu Grammatical analysis (PIKE, 1982 [1976], p. xiii):

\begin{abstract}
It should be clear that no technique could have been possible unless human nature across language barriers is in some sense uniform. This uniformity the theory attempts to capture. The theory's postulates, therefore, are affirmations about the universals of human nature, universals which work out through language (and also through nonlanguage behavior) so that there is a continuity of pattern from language to ceremony, from speech to football, from the design of automobiles to the structure of algebraic systems.
\end{abstract}

Para Pike, o tagmema faz parte dessa uniformidade, pois representa a relação entre dois universais inatos do comportamento humano: a unidade e o contexto. Essa relação é organizada por meio de um terceiro universal: a hierarquia. Logo no início do seu manual, Pike apresenta esses três universais como princípios teóricos (axiomas), dos quais derivam as implicações metodológicas da aplicação de sua teoria para a descrição de comportamentos linguísticos:

\footnotetext{
${ }^{9}$ Entre os anos 1940 e o início dos anos 1980, o Summer Institute of Linguistics, sob direção de Pike, havia descrito cerca de 600 línguas (1982). Pode-se dizer que Pike, no contexto cristão-protestante estadunidense do séc. XX, represente uma espécie de continuidade do trabalho de descrição linguística iniciado pelos missionários católicos dos sécs. XVI, XVII e XVIII nas Américas. Como foge completamente aos limites deste artigo, fica em aberto a questão sobre se a Tagmêmica de Pike representaria ou não (e em que sentido) essa continuidade e, além disso, se esta teoria estruturalista seria um indício da vitalidade da tradição que Sylvain Auroux abrevia com a sigla GLE (Gramática Latina Estendida) (2009 [1992]), da qual fazem parte, segundo Auroux, tanto as primeiras gramáticas dos vernáculos europeus quanto as das línguas não indo-europeias descritas pelos missionários católicos dos três primeiros séculos no Novo Mundo que os europeus começaram a descobrir a partir do final do séc. XV. Para uma identificação da influência de Santo Agostinho na GLE, recomenda-se a leitura da dissertação de Freitas (2016), trabalho orientado pelo Prof. Dr. Fábio da Silva Fortes (UFJF), em que se discute a Ars breuiata, seus antecedentes na Antiguidade Tardia - especificamente, Donato (séc. IV d.C.), e sua relação com outras obras de Agostinho: De magistro, De ordine e Doctrina Christiana.
} 
Principle 0.1 Unit: Purposive behavior, including language, comes in 'chunks', or constituents. (Language constituents such as words, sentences, stories, sounds, or noun phrases.)

COMMENT: Procedurally, therefore, we need techniques to find these chunks. We need to segment them from the stream of speech and to study them. Persons, things and events are also units.

[...]

Principle 0.2 Hierarchy (of Part-Whole): Hierarchy is seen when small units are found within larger ones, and these in turn in still larger ones.

[...]

Principle 0.3 Context: The analyst must, for some purposes, turn his focus away from specific units-as-if-they-were-not-in-context, since no unit is findable or definable except as in relation to context. (PIKE, 1982 [1977], p. 2-4)

Pike identifica três tipos de hierarquia em seus termos teóricos: fonológica, gramatical e referencial. O princípio a seguir define a primeira dessas hierarquias:

Principle $0.2 \mathrm{~b}$ Phonological hierarchy: the relation of sounds to their containing (including) syllables, stress groups, pause groups, and rethorical periods comprises the phonological hierarchy. (For example, the sound $s$ is in the syllable cats, which is stressed in the stress group the cáts, and so on.) (PIKE, 1982 [1977], p. 3)

De acordo com o princípio da hierarquia fonológica, os sons das línguas sempre aparecem em determinados contextos, ou seja, são sempre tagmemas (unidades-emcontexto). Nenhum desses contextos é aleatório, pois as variações de entonação nos stress groups, por exemplo, obedecem a outro princípio universal identificado pela Tagmêmica de Pike: a variação. É a partir do universal da variação que Pike generaliza suas perspectivas emic e etic para todos os comportamentos humanos:

Principle 0.1b Variation: When language is viewed as behavior, then units will inevitably have variants, since no single event (or word as seen as an event) can be repeated exactly by any man. When two utterances are structurally the same in the system (and hence identified as the same by the native speaker), they are (in tagmemic terms) said to be emically the same; and the differences between two utterances of the same emic unit are etic differences. (For example, pack may be said softly or loudly, faster or slower; each utterance is a phonetic variant, yet is recognized by the English speaker as being the same word (emic unit). Also a kind of furniture called table has many variants, yet is recognized as a table.) (PIKE, 1982 [1977], p. 2) 
Não é por acaso que Pike derivou o termo emic de phonemic e etic de phonetic (JONES, 1995, p. 316): a estrutura de relações linguísticas revelada pelos fonemas de uma língua significa uma constatação elementar do pressuposto mais geral da Tagmêmica de Pike: os comportamentos humanos, incluindo os linguísticos, só podem ser entendidos a partir de uma perspectiva universal. Apenas quando entendidos por meio de categorias universais, comportamentos particulares, como o conjunto dos fonemas de uma língua ou as regras de um jogo de baseball, terão significado.

Na Tagmêmica de Pike, portanto, um fonema é uma unidade emic, uma regra, que o falante nativo consegue distinguir nas várias ocorrências fonéticas de sua língua. Essas ocorrências fonéticas são as variantes etic dos sons constantes dessa língua (seus fonemas). Assim, uma possível definição de fonema na Tagmêmica de Pike seria: um fonema é uma estrutura de relações ou uma regra típica do sistema de sons constantes de uma língua.

Em entrevista a Karl J. Franklin (1996), Pike descreve como, frente a uma língua completamente desconhecida, a descrição torna-se possível:

FRANKLIN: [...] we have an absence of written records in most of the languages in which we work [...] it is impossible to provide an emic description of them [...] When we study proto-languages and then we can make certain observations about the food the people ate or how they lived, or make other comments, aren't we in some sense providing an emic description?

PIKE: [...], we guess at the emic structure, and we are going to be partly wrong. But if we don't assume that they had an emic structure, we have assumed that the people are not human, and then what is the point? So we have got to guess why people did what they did. We attribute things to them and we may be wrong. But in daily life, we guess that someone is talking because they want to tell us something, or they want to make us change something. So we are guessing all the time, and we're attributing certain intentions to others. [...] (PIKE, 1996, [n.p.])

Portanto, embora para Pike o ganho relativo de conhecimentos por parte de um linguista se dê por um processo inicial de conjecturas criticáveis (guessing), essas conjecturas se baseiam em universais humanos inatos que esse linguista deve pressupor como presentes em todas as línguas.

Como se vê, de acordo com pressupostos filosóficos da Tagmêmica de Pike, a análise linguística pressupõe categorias universais que devem ser entendidas como 
anteriores ao mundo. Portanto, pode-se dizer sem muita chance de errar que Pike optou por uma solução realista para os postulados de sua teoria.

\section{O fonema na Linguística Construtural}

Em abril de 2011, Geraldo Mattos concedeu uma entrevista a José Borges Neto, José Luiz Veiga Mercer e Alessandro Jocelito Beccari (MATTOS, 2011). Nessa entrevista, Geraldo Mattos descreveu acontecimentos importantes anteriores ao advento da LC. Um desses momentos foi uma conversa entre Eurico Back e Rosário Farani Mansur Guérios (1907-1987) sobre a necessidade de uma nova gramática escolar para a Língua Portuguesa:

BORGES NETO: Eurico contou uma vez, eu lembro disso, uma conversa que ele teria tido com o Mansur (Guérios) na Federal, que o Mansur o chamou no gabinete e disse: 'Você está estudando essa coisa de Tagmêmica, novas teorias e tal. Por que vocês não fazem uma gramática escolar [...] porque, o que existe por aí é tudo muito ruim. E aí o Eurico começou a pensar em fazer uma gramática da língua portuguesa [...].

GERALDO MATTOS (comenta): Uma gramática do português via Tagmêmica.

BORGES NETO: Tem alguma verdade nessa história?

GERALDO MATTOS: Eu tenho impressão que sim, porque, muito antes de começarmos, ele (Eurico) já estava coletando exemplos [... $]^{10}$ (MATTOS, 2011, [n.p.])

No trecho a seguir, Geraldo Mattos fala um pouco sobre a pesquisa de Eurico Back com a tagmêmica, nos anos 1960, e como o uso da técnica descritiva da tagmêmica para a Língua Portuguesa os levou a identificar um nível mais complexo da linguagem:

MERCER: Ele (Eurico Back) já tinha uma análise sintática diferente a essa altura (1969): lembra que aparecia naquele livro que ele fez: Roteiro de redação oficial?

MATTOS: (responde afirmativamente)

\footnotetext{
${ }^{10}$ Eurico Back foi discente do primeiro curso de especialização em Linguística do Brasil. O curso de Linguística fora implantado em 1963 na então nascente Universidade de Brasília (UnB) por outro paranaense: Ayron Rodrigues (1925-2014), que conhecera Mansur Guérios (1907-1987) no Ginásio do Paraná, onde Rodrigues estudou no final dos anos 1930. O curso de Linguística da UnB foi uma iniciativa do então Ministro da Educação, Darcy Ribeiro (1922-1997), através de um convênio que Darcy Ribeiro efetivou entre o Summer Institute of Linguistics (SIL) e a UnB (ALTMAN, 1998, p. 116).
} 
MERCER: O Roteiro de redação oficial é de antes disso: é de 1965. Lá, aquela análise sintática dele já é diferente da análise sintática tradicional.

MATTOS: Era já a Tagmêmica. Era reflexo da Tagmêmica.

MERCER (comenta): Já era por posições: 1, 2, 3...

MATTOS: É (reposta afirmativa).

BORGES NETO (comenta): Eu sou mais novo, fui teu aluno em '69... Aí já havia a parceria e havia a pesquisa.

MATTOS: Já havia parceria e pesquisa... em '70 e '71. Eu desconfio que em '69 nós trabalhamos lá mesmo na Católica, mas por nossa conta. Depois disso é que nós começamos a parceria e já pensando numa gramática. Mas, vejam, o Eurico já estava na Federal e no começo não era na Católica que nós trabalhávamos. Em '69 era lá na Federal... E foi lá que surgiu a palavra 'construtural'.

MERCER (comenta): A noção de construção e estrutura...

MATTOS: É. A Tagmêmica tinha construção e estrutura, mas em níveis diferentes! E nós colocamos a construção e a estrutura no mesmo nível. Aí é que eu disso para o Eurico: 'Eurico, não é mais Tagmêmica, nós estamos contra a Tagmêmica: esse é um princípio que torna diferente de tudo.' Ou seja, composição, etc., alinhamento... ficou tudo junto. (MATTOS, 2011, [n.p.])

De acordo com a LC, o princípio da construtura está em todos os níveis da linguagem: dos sons vocais aos diálogos mais complexos. No entanto, uma vez que a noção da linguagem como comunicação é central na LC, sua aplicação mais frequente do princípio da construtura é ao nível linguístico-comunicativo denominado cláusula. A cláusula constitui-se basicamente de dois enunciados: uma “solicitação”, da parte de um emissor, e uma “satisfação”, da parte de um receptor. Um exemplo de cláusula seria:

Emissor: - Onde trabalha você?

Receptor: - Trabalho aqui. (BACK; MATTOS, 1973, p. 15)

Como uma solicitação exige sempre uma satisfação e vice-versa, para a LC, enunciados como os da conversação acima codependem um do outro. Essa relação de codependência sintática, ao nível da cláusula, é o que a LC chama de construtura (BACK; MATTOS, 1973, p. 38).

Como a proposta inicial deste artigo é um estudo da ontologia do termo teórico “fonema” na LC, os níveis que a LC chama de "mais altos”, como a cláusula e o diálogo, não serão discutidos neste texto, cuja atenção se volta ao que a LC chama de nível fonológico. 
A LC entende por signo "um ente sensável (apreensível pelos sentidos) que representa os elementos de nossa cultura” (BACK; MATTOS, 1972, v. 2, p. 14) e distingue entre três tipos de signos: os indícios (como o riso, o choro), as figuras (como estátuas, mapas) e os sinais (signos convencionais: palavras, letras, notas). No sinal, como no signo de Saussure (2011 [1917], p. 130-141), são diferenciados dois elementos: "O sinal é uma forma porque nele coocorrem dois elementos: o significante e o significado.” (BACK; MATTOS, 1973, p. 39). Como assumem que o significante não existe sem o significado, Back e Mattos afirmam que esses dois elementos estão em uma relação de codependência: "significante e significado estão em codependência e o sinal é uma construtura” (id., p. 40).

O princípio da construtura se faz presente a partir da relação de codependência entre significante e significado: o signo possui um ou mais significados que codependem de uma construção de significantes. Esses significantes podem ser construções de fonemas e de entidades prosódicas que a LC chama de silabemas. Os silabemas são as sílabas rítmicas de um verso em um soneto, por exemplo.

Tanto o significante quanto o significado dividem-se em unidades mínimas: o significante divide-se em sílabas, que podem equivaler a fonemas ou a silabemas (BACK; MATTOS, 1973, p. 65-75); o significado divide-se em morfemas, que são unidades significativas mínimas.

Enquanto as sílabas constroem o que a LC chama de parte permanente do significante, os morfemas equivalem à sua dimensão imanente, pois só são inteligíveis ao falante que domina o código. Os criadores da LC chamam a construção das sílabas de melodia e denominam a estrutura imanente dos morfemas de tática. O significante é, assim, uma construtura, pois resulta da codependência entre dois elementos: uma construção melódica e uma estrutura tática.

A LC procura seguir Sapir em sua definição do fonema como um padrão cultural: um conjunto de fonias/sons constantes, mas que podem variar (alofones).

Como foi dito anteriormente, além do fonema, Back e Mattos identificaram outra entidade que corresponde a conjuntos de sons constantes na língua: o silabema. $\mathrm{O}$ silabema é o elemento rítmico de uma língua particular de acordo com o caráter dessa língua. O silabema é a repetição de uma sílaba com a mesma prosódia em intervalos iguais. Cada língua teria seus próprios silabemas e, como resultado disso, sua própria 
rítmica. Nesse ponto, os criadores da LC aproximam-se da compreensão humboldtiana das línguas como expressões de universos culturais:

A compreensão e interpretação do mundo, a visão do universo segundo Humboldt, dependem da cultura de cada povo e a cultura se espelha, melhor, é retratada de alguma forma pela língua: a língua de cada povo é capaz de transmitir todos os fatos de sua cultura. (BACK; MATTOS, 1973, p. 66)

Na verdade, a citação explícita de Humboldt no Manifesto da LC é prova de sua influência (KOERNER, 2014, p. 91-102).

Como se viu acima, a cláusula manifesta o princípio da construtura, pois os elementos que a constituem estão em codependência. Assim, o sentido da "solicitação" que começa com um vocábulo como "Onde" completa-se com o sentido de uma “satisfação” que termine com um vocábulo como “aqui”.

Fonologicamente, a cláusula também é entendida como uma construtura, porque, somados aos seus conteúdos imanentes, os dois enunciados da cláusula são vistos como alinhamentos de sílabas que constituem a melodia (entonação típica) dos seus significantes: uma pergunta tem uma entonação diferente de uma afirmação, por exemplo, e essas entonações variam de uma língua para outra.

Embora os criadores da LC assumam universais da linguagem, como faz Pike, esses universais não são entendidos como autônomos ou anteriores à experiência, mas como dependentes de situações. Como povos diferentes vivenciam situações diferentes, a satisfação de suas necessidades dependerá das compreensões que tiverem de suas situações particulares. Na língua, essas compreensões são os significados, que são transmitidos culturalmente de geração a geração por meio de vocábulos, que são construídos por padrões de sons. A LC chama a dependência dos significados nas situações que os determinam de aspecto "dinâmico" do significado (BACK; MATTOS, 1972, p. 472, v. 2), pois os significados mudam de acordo com as situações.

O aspecto dinâmico do significado exige que qualquer vocábulo de uma dada língua faça referência a um comportamento característico de seu universo cultural. Sendo assim, o surgimento de um vocábulo em uma língua depende da situação social da população que o originou: populações pesqueiras desenvolvem vocabulários 
pesqueiros, tribos das planícies do Arizona desenvolvem vocabulários topográficos complexos (BACK; MATTOS, 1973, p. 65).

Portanto, na LC, as línguas não se organizam a partir de categorias anteriores à experiência, mas se parecem mais com enciclopédias de conhecimentos padronizados a respeito de mundos culturais distintos. O falante de uma língua aprende por imitação a intuir esses conhecimentos linguísticos padronizados da mesma maneira que aprende outros padrões culturais: gestos, costumes, crenças, etc. Portanto, na LC, uma definição do fonema poderia ser: um fonema é um padrão cultural: um padrão de sons constantes e de sons variáveis. Nesse sentido, dos três autores do Estruturalismo Norte-americano que este artigo considerou, a LC de Back e Mattos se aproxima mais de Sapir, no que tange a sua definição de fonema, do que de Bloomfield ou Pike. Na verdade, os próprios criadores da LC acreditam nessa semelhança: “O fonema não é conjunto de traços fônicos (fonias) distintivos [...] a fonia [...] é uma constante, faz parte do fonema. Cremos que está implícito no termo ‘padrão’ de Sapir ${ }^{11 ”}$ (BACK; MATTOS, 1973, p. $67)$.

Além de Sapir, Back e Mattos (1972) apontam, no horizonte de retrospecção de sua teoria, Wihelm von Humboldt (1767-1835) e Santo Agostinho (354-430):

[...] o conceito tradicional de significado é estático, mantém-se fora da atividade lingüística e, justamente por isso, equivale a uma representação mental, baseada em memória. Sob um aspecto dinâmico, o significado é a associação entre o significante e uma situação cultural. Com esse conceito e significado, não só o surpreendemos objetivamente, mas ainda podemos analisá-lo cientificamente, $[\ldots]$

[...] Declaramos velha a idéia. E é. Cedamos a palavra a Santo Agostinho, que nos relata algumas de suas experiências: [...] $]^{12}$

Delineia-se aí ${ }^{13}$ em palavras inequívocas o código subjacente, além do conceito sucinto do significado como associação de significante a situação cultural. (BACK; MATTOS, 1972, p. 472-473, v. 2)

\footnotetext{
11 Outro indício da importância de Edward Sapir para a LC é o fato de este ser o único autor da Linguística norte-americana que tem uma de suas obras citada no item “Autores citados” do Manifesto de 1973. Trata-se da Lingüística como ciência, ensaios, publicada em 1961 pela Livraria Acadêmica, Rio de Janeiro, com tradução de Mattoso Câmara Júnior (1904-1970).

12 Os autores fazem aqui citação ao Livro I, §13, das Confissões de Santo Agostinho, em que o bispo de Hipona relata sua experiência de aprendizado do sentido das palavras a partir da observação da repetição de gestos faciais, movimentos do corpo e entonações de voz de pessoas adultas. Um tratamento mais aprofundado da influência de Santo Agostinho na LC exigira uma exploração mais detida e cuidadosa das ideias linguísticas do bispo de Hipona. Essa reflexão pode ser feita a partir de futuras pesquisas sobre o assunto e da leitura da dissertação de Freitas (2016).
} 
A hipótese de que a teoria de Back e Mattos é de base conceitualista não é confirmada diretamente por Mattos na entrevista de abril de 2011. Todavia, nessa mesma entrevista, Mattos cita um livro sobre estilística que ele havia escrito antes da Gramática construtural da língua portuguesa (1973), em que a ideia de cláusula já estava presente no nível fonológico: um livro em que ele já utilizava termos teóricos que lembram os da LC:

BORGES NETO: Você lembra mais ou menos como é que foi a cronologia da construtural? [...] Em 1970, provavelmente, em uma das aulas de língua portuguesa, você chegou e disse, assim: 'tenho uma novidade, descobrimos um nível estrutural novo’, que era o nível da cláusula. E, portanto, a cláusula é uma parte da gramática construtural que é mais tardia, digamos, do que outras. Tem idéia de onde vocês começaram? A semântica é posterior, a estilística...?

GERALDO MATTOS: Bom, a estilística, eu tenho um livro sobre a estilística anterior à construtural ${ }^{14}$.

BORGES NETO (comenta): E que é bastante parecido já...

GERALDO MATTOS: É que é igual, porque, na cláusula, tem a palavra de um primeiro emissor para um receptor e depois tem a resposta do emissor. Então, o primeiro é um essencial e o outro é um acidental! E essencial e acidental é a base fundamental. (MATTOS, 2011, [n.p.])

A Estilística de Geraldo Mattos é um capítulo à parte da LC, pois parece conter observações de interesse tanto para a Fonologia quanto para a Linguística Histórica. A noção central da Estilística de Mattos parece ser o silabema.

$\mathrm{Na}$ dupla articulação da linguagem da LC, os fonemas são elementos permanentes do significante (acidental), que codependem com o significado imanente (essencial). Quando as sílabas são silabemas (sílabas rítmicas), definem o ritmo de uma língua, o que, de acordo com o pensamento humboldtiano dos criadores da LC, representa a expressão típica da cultura linguística de um povo: sua poesia ${ }^{15}$.

\footnotetext{
${ }^{13}$ Os autores referem-se ao trecho, que acabam de citar, das Confissões de Santo Agostinho. Cf. nota anterior.

${ }^{14}$ Trata-se do livro Estilística da língua portuguesa, publicado em 1969 pela editora SPELL, em Curitiba.

${ }^{15}$ Esse interesse de Mattos por poesia tem a ver com sua formação e pesquisas anteriores a seus primeiros contatos com a Tagmêmica. A tese de livre docência de Eurico Back intitula-se Fonêmica diacrônica latino-portuguesa e é de 1964, portanto, suas pesquisas filológicas eram provavelmente concomitantes ao seu curso de Linguística na UnB. Na trajetória de Geraldo Mattos como pesquisador, porém, algo um pouco diferente parece ter acontecido: sua tese de doutoramento, O cancioneiro do clérigo Ayras Nunes, é de 1962, e ele só veio a entrar em contato com a Tagmêmica através de um curso ministrado por Eurico Back entre 1965 e 1969 na Universidade Católica do Paraná (MATTOS, 2011). A formação filológica e literária de Mattos foi, segundo ele mesmo, seminarística (ele cursou os ensinos fundamental e médio em
} 


\section{Considerações finais}

A partir das discussões acima, tem-se as seguintes considerações:

1) Na terminologia da LC, o fonema é o elemento mediato (não significativo) e constante do sinal, que pode variar de acordo com as situações e adquirir novos significados, que a LC chama de significados estilísticos lexicais. Por exemplo, o uso do fonema /k/ em um verso do poema "O Cacto” de Manuel Bandeira citado no Manifesto (1973, p. 63). Em sua definição do fonema, portanto, a LC difere da Linguística de Bloomfield, para quem o fonema é tão-somente uma nomenclatura que resume um conjunto de sons humanos distinguíveis no contínuo da fala. Na LC, o fonema é um padrão cultural constante e variável a que se tem acesso intuitivamente e que pode ser modificado de maneira criativa.

2) Conforme depoimento de Geraldo Mattos (2011), a LC origina-se em um método de descrição que Eurico Back derivou da Tagmêmica e aplicou, no decorrer da década de 1960, a ocorrências do Português Literário do Brasil. De fato, a LC importa conceitos como classe, forma, tagmema, êmico, ético, etc., da Tagmêmica. Todavia, na LC, categorias universais não parecem ser anteriores a situações culturais. Logo, o realismo da Tagmêmica de Pike não parece ser a resposta que os criadores da LC dão para o problema ontológico.

3) Na “Conclusão” de seu Manifesto, Back e Mattos afirmam que a linguagem humana é um conjunto de fatos fundamentais. Esses fatos, segundo eles, devem ser estudados de acordo com o método dedutivo "defendido por Hjelmslev" (BACK; MATTOS, 1973, p. 114), em que o conceito básico é a relação (HJELMSLEV, 1975 [1943] p. 39-45). Além disso, como em Hjelmslev, os autores apresentam a LC “como conjunto de constantes e variáveis” (BACK; MATTOS, 1973, p. 115): a linguagem é, para eles, como em Hjelmslev (1975 [1943]) um sistema de elementos constantes (BACK; MATTOS, 1973, p. 113) de que podem ser deduzidos os fatos da língua. No entanto, diferentemente da definição de teoria da linguagem de Hjelmslev, Back e Mattos (1973) não identificam sua teoria com um conjunto de possibilidades independentes ou anteriores a suas realizações empíricas, o que equivale a "um sistema dedutivo puro” (HJELMSLEV, 1975 [1943], p. 16). Para os criadores da LC, uma teoria

seminários católicos franciscanos nas décadas de 1940 e 1950) e não se vincula ao seu curso de Letras na PUC-PR (id.). 
linguística não pode ser um sistema puro, anterior à experiência, porque a linguagem é inseparável das línguas e estas resultam de situações culturais particulares. Ou seja, embora partilhem do método dedutivo de Hjelmslev, a ontologia de Back e Mattos (1973) vai em direção contrária à do linguista dinamarquês.

4) O termo teórico "fonema” da LC parece aproximar-se da noção de fonema como uma realidade social e psicológica que equivale a um padrão ou comportamento cultural padronizado e padronizável. Se essa for a resposta que a LC dá ao problema ontológico com relação ao fonema, parece assemelhar-se mais à resposta conceitualista de Sapir do que à nominalista de Bloomfield ou à realista de Pike. Assim, ao menos do ponto de vista da definição do termo teórico “fonema”, a LC parece oferecer uma construção teórica com pressupostos semelhantes à linguística de Sapir.

Portanto, embora tenham adaptado o método descritivo de Pike (BACK; MATTOS, 1972; 1973; MATTOS, 2011) e o método dedutivo de Hjelmslev (BACK; MATTOS, 1973, p. 114) na criação de sua teoria, os autores da Gramática construtural da língua portuguesa parecem pertencer a uma tradição conceitualista na história dos Estudos da Linguagem e não a uma realista, como a de Pike ou a de Hjelmslev. De fato, como foi visto na seção anterior, os próprios Back e Mattos remontam seus pressupostos epistemológicos a Sapir, Humboldt e Santo Agostinho.

BECCARI, Alessandro Jocelito. The ontology of the phoneme in the linguística construtural [constructural linguistics] of Back (1923-2003) and Mattos (1931-2014). Revista do Gel, São Paulo, v. 14, n. 1, p. 133-156, 2017.

Abstract: The city of Curitiba was one of the first places in Brazil where Linguistics became a university subject. The University of Parana provided its students with linguistic theories as early as the 1950s. The Linguistic Circle of Curitiba was created with its journal, Revista Letras, in 1953. Then, in the 1960s, in the Catholic University of Parana, professors Eurico Back (1923-2003) and Geraldo Mattos (1931-2014) proposed a Structuralist theory called Linguística Construtural (LC) [Constructural Linguistics - CL], developing substantial literature and forming a generation of linguists (BORGES NETO, 2013, p. 17). The purpose of this article is to reflect on a central concept of CL: its notion of phoneme. For this, some of Back and Mattos' works will be examined; in particular, their Gramática construtural da língua portuguesa [Constructural Grammar of Portuguese language] of 1972, its Manifesto, published in the first number of the journal Construtura and an interview with Mattos in 2011. In the considerations to be made, the assignment of relevant importance to theoretical entities 
is seen as a prerequisite for the epistemological understanding of the basic assumptions of linguistic theories; such thesis has been argued by Borges Neto $(1991,2004)$ and Dascal (1978, 2004).

Keywords: Linguistic Historiography. Philosophy of Linguistics. Constructural Linguistics.

Submetido em: 20/06/2016.

Aceito em: 12/08/2016.

\section{Referências}

AGOSTINHO. Confissões. São Paulo: Paulinas, 1984.

ALTMAN, C. A pesquisa lingüística no Brasil (1968-1988). São Paulo: Humanitas/Publicações FFLCH/USP, 1998.

AUROUX, S. A revolução tecnológica da gramatização. Campinas: Editora da UNICAMP, 2009 [1992].

BACK, E. Fonêmica diacrônica latino-portuguesa. 1964. 86 f. Tese (Livre-Docência em Filologia Românica) - Setor de Ciências Humanas, Letras e Artes, Universidade Federal do Paraná, Curitiba, 1964.

BACK, E.; MATTOS, G. Gramática construtural da língua portuguesa. v. 1. São Paulo: FTD, 1972.

Gramática construtural da língua portuguesa. São Paulo: FTD, 1972, v. 2. 129, 1973.

Lingüística Construtural: Manifesto. Construtura, São Paulo, v. 1, n. 1, p. 1-

BLOOMFIELD, L. Language. New York: Holt, Rinehart and Winston, 1961 [1933].

BORGES NETO, J. A gramática gerativa transformacional: um ensaio de filosofia da linguística. 1991. 277 f. Tese (Doutorado em Estudos Linguísticos) - Instituto de Estudos da Linguagem, Universidade Estadual de Campinas, Campinas, 1991.

A Linguística Construtural: um capítulo da história da lingüística no Brasil. Revista Letras, Curitiba, n. 87, p. 15-38, jan.-jun. 2013.

BORGES NETO, J.; DASCAL, M. De que trata a lingüística, afinal? In: BORGES NETO, J. Ensaios de filosofia da lingüística. São Paulo: Parábola, 2004. p. 31-65. 
CHIERCHIA, G. Reference to kinds across languages, Natural Language Semantics, The Netherdlands, v. 6, p. 339-405, 1998.

DARNELL, R. Franz Boas, Edward Sapir, and the americanist text tradition. In: North american contributions to the history of linguistics. DINNEEN, F. P.; KOERNER, E. F. K. (Ed.). Amsterdam/Philadelphia: John Benjamins, 1990. p. 129-144.

DASCAL, M. As convulsões metodológicas da lingüística contemporânea. In: DASCAL, M. (Org.). Fundamentos metodológicos da linguística: concepções gerais da teoria linguística. v. 1. São Paulo: Global, 1978. p. 16-41.

ERFURT, T. de. Grammatica speculativa sive de modis significandi. Traduzido e editado por G. L. Bursill-Hall. London: Longman, 1972.

FRANKLIN, K. J. K. L. Pike on etic vs. emic: a review and an interview. 1996.

Disponível em: <http://www.sil.org/klp/karlintv.htm> Acesso em: 18 jul. 2011.

FREITAS, F. A. de S. O pensamento gramatical de Santo Agostinho. 2016. 158 f. Dissertação (Mestrado acadêmico em Linguística) - Faculdade de Letras, Universidade Federal de Juiz de Fora, Juiz de Fora, 2016.

GILSON, E. A filosofia na Idade Média. São Paulo: Martins Fontes, 1998 [1922].

HJELMSLEV, L. Prolegômenos a uma teoria da linguagem. São Paulo: Perspectiva, 1975 [1943].

JONES, L. K. Tagmemics. In: KOERNER, E. F. K.; ASHER, R. E. (Org.). Concise history of the language sciences: from the Sumerians to the cognotivists. Oxford: Elsevier, 1995. p. 315-319.

KOERNER, E. F. K. Models in linguistic historiography. In: KOERNER, E. F. K. Practicing historiography: selected essays. Amsterdam/Philadelphia: John Benjamins, 1989. p. 47-59.

O problema da influência na historiografia linguística. In: KOERNER, E. F. K.

Quatro décadas de historiografia linguística: estudos selecionados. Centro de Estudos em Letras da Universidade de Trás-os-Montes e Alto Douro, Col. Linguística II, 2014. p. 91-102.

LIDDEL, H. G.; SCOTT, R. A lexicon abridged from Liddell and Scott's GreekEnglish lexicon. Oxford: Clarendon Press, 1974 [1843].

MATTOS, G. O cancioneiro do clérigo Ayras Nunes. 1962. 94 f. Tese (Doutorado em Filologia Românica) - Setor de Ciências Humanas, Letras e Artes, Universidade Federal do Paraná, Curitiba, 1962.

Estilística da língua portuguesa. Curitiba: SPELL, 1969. 
A Lingüística Construtural. Entrevista concedida a José Borges Neto, José Luiz Veiga Mercer e Alessandro Jocelito Beccari. Curitiba, abr. de 2011. Registro em arquivo de áudio digital (124 min).

OCKHAM, W. Quodlibeta Septem. In: Os pensadores. Tomás de Aquino, Dante, Duns Scot, Ockham: seleção de textos. São Paulo: Abril, 1979 [c. 1327].

PIKE, K. L.; PIKE, E. G. Grammatical analysis. Dallas: Summer Institute of Linguistics, 1982 [1977]. Disponível em:

<http://www.sil.org/acpub/repository/41339.pdf> Acesso em: 18 jul. 2011.

ROBINS, R. H. Pequena história da lingüística. Rio de Janeiro: Ao Livro Técnico, 1983 [1967].

ROGERS, D. E. The influence of Pānini on Leonard Bloomfield. In: HALL, Jr. R. A.; KOERNER, E. F. K. (Eds.). Leonard Bloomfield: essays on his life and work. Amsterdam/Philadelphia: John Benjamins, 1989. p. 85-138.

SAPIR, E. The status of linguistics as a science: discurso para a reunião conjunta da Linguistic Society of America (LSA), da American Antropological Association (AAA) e das Seções H e L da American Society for the Advancement of Science, de 1929. Language, v. 5, p. 207-214, 1929.

The psychological reality of phonemes. In: MANDELBAUM, D. G. (Ed.). Selected Writings of Edward Sapir in Language, Culture and Personality. Berkeley/Los Angeles/London: University of California Press, 1949 [1933]. p. 46-60.

SAUSSURE, F. de. Curso de lingüística geral. São Paulo: Cultrix, 2011 [1917].

SCOTUS, J. D. Opus Oxoniense. In: SCOTUS, J. D. Os pensadores. Tomás de Aquino, Dante, Duns Scot, Ockham: seleção de textos. São Paulo: Abril, 1979 [c. 1300].

SWIGGERS, P. Nuevas aportaciones a la historiografía lingüística. In: Congresso Internacional de la SEHL, 4, 2003, La Laguna (Tenerife), Actas... La Laguna: Arco/Libros, 22 al 25 de octubre de 2003. p. 113-145. 